\title{
TYPICAL WORK ENVIRONMENT RISKS, THEIR CAUSES AND REDUCTION MEASURES IN CONSTRUCTION
}

\author{
Maris Ziemelis ${ }^{1}$, Dr.sc.ing./Assist.Prof.; Vladimirs Jemeljanovs ${ }^{2}$, Dr.sc.ing./Prof. and Jelena \\ Malahova ${ }^{3}$, Dr.oec./Assoc.Prof. \\ $1,2,3$ Riga Technical University, Latvia
}

\begin{abstract}
The aim of the paper is to identify the most typical and dangerous work environment risks in construction and their causes, put forward the proposals for risk reduction. Comparison and grouping methods for the analysis of statistic data, as well as methods and schemes for evaluating work environment risks were used in the research. Proposals for reducing the causes of the most typical and hazardous risks are presented in the paper. Specific solutions for each of hazardous risks and their causes are offered paying particular attention to the means of collective protection, as well as a model of corporate system is offered to regulate the procedures by which employees should be instructed and examined in order to improve the quality and control of labour protection instructions in construction for companies.
\end{abstract}

Key words: labour protection, risks, environment risk.

JEL code: R19, L89, F60.

\section{Introduction}

The construction sector is one of the largest economic sectors of Latvia and the European Union by number of employees and financial turnover. During the economic crisis, construction volumes of the sector fell significantly and a highly skilled workforce went in search of jobs outside the country's borders, which contributed to the lack of highly skilled professionals in Latvia. As construction volumes increased after the years of crisis, workers with lower qualifications and fewer working experience got involved in the construction market.

From the point of view of labour protection, construction is considered to be one of the most dangerous areas in national economy, which is characterised by large number of employees' accidents as well as occupational diseases more often than on average in Latvia. Construction is one of the sectors where completely all the risks of work environment can be identified, from them specifying the most typical and hazardous that result in serious and fatal accidents. This is related to the fact that construction works vary widely, works of different types are carried out at the same time by a large number of employees of different professions and with varied professional training level and the works should be performed in short periods of time and different weather conditions. All of this generally contributes to a high risk of the work environment in construction, accidents of varying degrees. However, the basis of everything is a lack of understanding of labour protection issues on the part of employers, as well as employees and contractors (Riga Stradins University, 2011). In order to avoid dangerous situations, the employees should be instructed and experienced, which contributes to their safety and the safety of their co-workers.

The complex of successful actions is based on a system, and labour protection system in construction companies is of great importance in creating safe and health-friendly work environment. In construction companies, labour protection system should be focused on close co-operation between employees and employers, searching for common solutions. The system is essential for development of a qualitative and effective performance of instruction in labour protection, for consolidation of employees' knowledge and practical skills.

\footnotetext{
${ }^{1}$ Corresponding author. Tel.: +371 29178601, E-mail address: maris.ziemelis_1@rtu.lv

2 Corresponding author. Tel.: +371 29475029, E-mail address: vladimirs.jemeljanovs@rtu.lv

${ }^{3}$ Corresponding author. Tel.: +371 26414433, E-mail address: jelena.malahova@rtu.Iv
} 


\section{Accident statistics in the construction sector in Latvia}

From the point of view of labour protection, construction is considered to be a rather dangerous sector, where each year there occur dozens of accidents and employees suffer lasting health problems, i.e. occupational diseases (Riga Stradins University, 2016).

According to the accident statistics of the State Labour Inspectorate, there has been a total of 12.446 accidents at work during the period 2009-2016, of which 1.086 in construction, i.e. an average of $8,7 \%$ of the total (Table 1 ).

Table 1

Statistics on the number of accidents in construction sector in Latvia from 2009 until 2016

\begin{tabular}{|c|c|c|c|c|c|c|c|c|c|}
\hline & 2009 & 2010 & 2011 & 2012 & 2013 & 2014 & 2015 & 2016 & Total \\
\hline \multicolumn{10}{|c|}{ Accidents in work places } \\
\hline Nationwide & 1.203 & 1.232 & 1.397 & 1.545 & 1.748 & 1.763 & 1.712 & 1.846 & 12.446 \\
\hline $\begin{array}{l}\text { Construction } \\
\text { sector }\end{array}$ & 120 & 102 & 138 & 174 & 157 & 149 & 122 & 124 & 1.086 \\
\hline$\%$ & 10 & 8 & 10 & 11 & 9 & 8 & 7 & 6.7 & 8,7 \\
\hline \multicolumn{10}{|c|}{ From them: serious accidents in work places } \\
\hline Nationwide & 175 & 175 & 196 & 219 & 230 & 213 & 166 & 184 & 1.558 \\
\hline $\begin{array}{l}\text { Construction } \\
\text { sector }\end{array}$ & 37 & 27 & 30 & 41 & 45 & 42 & 22 & 39 & 283 \\
\hline$\%$ & 21 & 15 & 15 & 19 & 20 & 20 & 13 & 21 & 20,7 \\
\hline \multicolumn{10}{|c|}{ lethal accidents in work places } \\
\hline Nationwide & 32 & 25 & 34 & 35 & 31 & 41 & 41 & 38 & 277 \\
\hline $\begin{array}{l}\text { Construction } \\
\text { sector }\end{array}$ & 7 & 5 & 10 & 11 & 3 & 5 & 2 & 5 & 48 \\
\hline$\%$ & 22 & 20 & 29 & 31 & 10 & 12 & 5 & 13 & 17,3 \\
\hline
\end{tabular}

Source: authors' construction based on the date of the State Labour Inspectorate

As a whole, the trend over the years shows that the number of accidents is declining, while 2016 data show that severe and fatal cases have increased compared to 2015. In general, this shows the trend of improving the attitudes of entrepreneurs and workers towards labour protection and the culture of workforce themselves from year to year.

The most common causes of serious and fatal accidents are non-compliance with safety regulations or instructions ( $27 \%$ ), unsatisfactory instruction and training of workers (14\%) and insufficient attention (12\%) (State Labour Inspectorate, 2015).

\section{The most common work environment risks in construction}

Typical work environment of construction sites has the following characteristic features:

- a constantly changing work place at different sites;

- a lot of heavy machinery and equipment;

- significant levels of noise, vibration, dust and various chemicals;

- high risk of transport accidents at sites (Riga Stradins University, 2016).

Statistic data show that accidents at construction work places in Latvia mostly occur due to lack of attention of employees and failure to comply with the specified labour protection requirements. A large part of identified occupational diseases have developed due to both poor and dangerous working conditions, failure to comply with elementary labour protection requirements and lack of caution. This is why it is important for employers, labour protection specialists and employees to be informed about the essential labour protection requirements, the most dangerous factors of work environment and possible labour protection measures when working in this sector (Riga Stradins University, 2016). 
The safety and health of employees are the most important aspects from the point of view of labour protection, which should not be threatened due to the influence of different work environment risk factors. Of course, it should be noted that failure to comply with labour protection requirements can also cause financial loss to a company (equipment, raw materials, etc. can be damaged) and "third persons" employees of other employers working at the site, passers-by or other people close to sites can suffer. Environmental contamination may also occur (for example, leakage of chemicals - paints, solvents etc.) (Riga Stradins University, 2016).

From the point of view of employees' safety and health, risk factors at construction sites may have a significant impact on the health of employees.

Essential aspect is the rapid pace of construction, which defines the continuous variability of a construction site. Technology changes quickly, subcontractors have different working methods, used equipment and chemicals etc., and, therefore, working conditions and risks employees are exposed to are variable. Lack of time and urgency during implementation of construction projects are an additional aspect which has a direct impact on the level of labour protection. Unfortunately, employers and contractors often believe that time and money can be saved at the expense of labour protection. For example, in order to reach a wall above $1,5 \mathrm{~m}$ or access the ceiling, one cannot do without sound scaffolding, so it needs to be raised, but railing is optional, because work can be done anyway. Similar thing happens when one does the roofer's job. Safety belt and safety ropes are uncomfortable so a worker cannot move fast and do the job as quickly as without these safety measures. In both cases ignoring of safety requirements essentially reduces work quality and increases the risk of accidents. Therefore, it should be remembered that, in case of an accident, costs will be higher than while respecting safety rules (Riga Stradins University, 2016).

Major factors leading to accidents occurring in construction:

- work at a height without protective fencing and inappropriate scaffolding, which creates a risk of falling, as well as work at a height on mobile ladders, and non-use of individual anti-fall protective equipment;

- drop of objects;

- snagging, stumbling in a disordered workplace etc.;

- electrical injuries, danger of explosion;

- various accidents involving the driving of heavy machinery (cranes, lorries etc.);

- work with work equipment and hazardous equipment (cranes, pulleys, lifts etc.);

- work in trenches without shoring (Riga Stradins University, 2016).

Work at a height is widely spread in a large number of sectors, particularly, in construction, building maintenance, energy and telecommunication, but employers, employees and even persons responsible for labour protection often underestimate the risks that may be the cause for falling from height. The accidents related to falling from height usually have serious consequences for employees' health and can cause their death. Therefore, it is necessary to timely plan the works where falls from height may be minimised by performing risk assessment and envisaging sufficient and adequate preventive measures (Riga Stradins University, 2011).

Falling from small height is dangerous because the fall time is very short - for falls from height up to $5 \mathrm{~m}$ it is less than or equal to the average response time (Riga Stradins University, 2011).

To prevent the danger of falling from height, one should use:

1) Collective labour protection equipment (for collective labour protection measures):

- preventing falls (railings, scaffolding, coverings etc.); 
- receptive equipment (anti-fall networks, absorbing pillows etc.);

2) Individual protection equipment (anti-fall systems) (Riga Stradins University,2011).

Work in trenches and foundation pits is very common in construction. While performing the works, basic labour protection requirements are not observed and accidents occurring have very serious consequences or end up with victim's death. Usually people are threatened by landslides from trenches without shoring or employees are hit by excavated land or other materials. Such risks are especially increased by heavy machinery working in the vicinity of trenches or other employees. In some cases, not reported in the project communication systems (gas pipeline, electricity cable) or explosive objects must be encountered. The risks related to getting in and out of a trench should also be mentioned (Riga Stradins University, 2016).

Noise in construction is a very common work environment risk factor. It is caused by a variety of work equipment (such as perforators, saws, mixers, angle grinding machines etc.) and heavy machinery. Starting each machine creates noise - a chaotic mix of sounds of different frequencies and varying intensity, which can significantly exceed the permissible (safe) level (Riga Stradins University, 2016). Noise exposure level within normal working hours must not exceed $87 \mathrm{~dB}(\mathrm{~A})$ or a peak level $140 \mathrm{~dB}(\mathrm{~A})$. If the noise exposure limit value is exceeded, labour protection measures should be taken immediately to reduce noise exposure level to the exposure limit value of $87 \mathrm{~dB}(A)$.

At work places where the noise level exceeds the lowest noise exposure action value $80 \mathrm{~dB}(A)$, the employer should provide:

1) Employees with individual hearing protection means;

2) Training and instruction for employees and trusted persons regarding the risk caused by noise paying particular attention to:

- the nature of risk caused by noise and risk for employees' hearing and other organ systems likely to occur due to noise;

- labour protection measures taken and to be taken to reduce or prevent the risk caused by noise and the conditions under which these measures are to be taken, specifying in particular the measures to be taken by employees themselves;

- the correct use of individual hearing protectors;

- the importance of hearing testing and signs of hearing damage, as well as reporting to the employer of hearing worsening;

- the conditions in which employees are entitled to health checks and the importance of these checks;

- safe working methods to reduce exposure to noise (Labour Protection Requirements..., 2003).

Vibration is a very common factor in work environment that should be encountered with operating of most equipment that causes not only noise but also vibration when working. Vibrations are usually based on poorly balanced rotational or directional components and the occurrence of vibration is determined by the operating principles of the equipment. Construction workers are often affected by arm and hand, as well as by whole body vibration. To arms and hands vibration is transmitted through employee's hands with work equipment the operation of which is based on strokes and rotation. Whole body vibration is transmitted through the supporting surfaces of a stationary or seated worker and affects the whole body (Riga Stradins University, 2016).

Chemicals and dust are a daily phenomenon in construction that arises from both the fuel used and from the construction materials. 
Essential risk factor in construction is dust which can occur in the process of performing almost all construction works. Abrasive dust and abrasive particles (derived from grinding), lime and chalk dust, silicate dust, wood, concrete and cement dust (silica dust) are most widespread in construction. Glass and stone waddings are often used in construction. Some dust is held off by the hair of the nose, a portion of the passage lands in the wet mucosa, and other dust particles are held in the throat and laryngeal membranes. The lining of the nose not only stops, but thanks to the bactericidal properties, also kills bacteria. The most harmful are microscopic dust, particularly particles of 0,52,5 mm size, which is capable of entering deep airways, even alveolus, which causes acute inflammation, which can then pass into chronic inflammation. Asbestos containing dust is especially harmful, asbestos fibres are a proven occupational carcinogen (Riga Stradins University, 2016).

The most common problems in construction are the misuse of different chemicals (construction materials or different consumables) and the lack of awareness of the hazards of workers, as well as the storage of these substances in unsuitable and unlabelled containers. Very often workers are not provided with correct and appropriate individual protective equipment, such as gloves and respiratory protective devices (Riga Stradins University, 2016).

Handling weights, forced posture, frequent and repetitive movements are ergonomic risk factors. It should be noted that "weight" is a notional size, whether the object is heavy, depends on the individual characteristics of the employee. Forced postures, body or its parts being in a long-term constant state. Forced postures can be very different - sitting, standing, walking, lying, squatting, bending and stretching. Depending on their type, forced posture can affect the neck and shoulder band, elbows and hands, back, hips or legs. In construction, the most frequent forced postures are associated with long-term tufting on the knees (e.g. flaps, roofers) or long-term sitting (Riga Stradins University, 2016).

Construction may involve frequent and repeated movements in many working processes; particularly harmful if requires an expressed physical effort of more than $50 \%$ of working time, such as grinding, plastering, painting and other interior works (Riga Stradins University, 2016).

\section{Options for reducing the causes of trenching risks}

The analysis of accident statistics, more specifically, the number of fatal accidents, revealed that trenches are among the most dangerous in terms of the number of fatal accidents. The risk assessment for a particular situation identified the most dangerous risks of strengthening trench walls as well as getting in, getting out and moving along the trench. Also a major risk is an unordered and unplanned construction site, which creates a chaotic interaction between workers and heavy machinery moving around the construction site.

To reduce risks before starting work, it is necessary to correctly understand the task of the work to be carried out in order to ensure full protection against accidents, and it is therefore important to attract the competent persons and bodies to assess, draw up and give an opinion on:

- the soil composition;

- preparing a labour protection plan for a specific object (designing PPE and CPE);

- the absence of engineering communications in the work area or a plan to protect engineering communications;

- a work project accepting the interaction between construction machinery and workers on the construction site, with a particular focus on correctly strengthening the walls of trenches, building pits; 
- high-quality instructions for a specific object with the specific nature of its work.

It is prohibited to dig holes and trenches without additional corroboration if they exceed the following depths:

- in sand ground - more than 1 metre;

- in moor sand ground - more than 1,25 metres;

- more than 1,5 metres in sandy and clay soil;

- on hard ground, when crowbars and hacks are used - more than 2 metres (Riga Stradins University, 2010).

Building pits and trenches must be constructed with slanted walls without corroboration or with vertical walls, securing them throughout the height. The walls must also be strengthened if there is a risk of collapse of the edges.

In order to get in and out of the trench, it is necessary to use tested ladders which need to be stabilised, so that there is No risk of falling down during climbing and creating an accident risk. If there is less place in the trench, the portable ladders should be selected, but the ladders should preferably be placed on a stable surface, with the possibility of fixing them preventing the possibility of movement, as well as the length of the stairs must extend sufficiently across the edge of the trench to allow workers escape the trench freely.

During trenching and digging works, workers are at risk of injury from construction equipment located on the site, it is therefore important to plan correctly the work of the machinery and workers on the construction site.

If technical works are carried out adjacent to an unfixed trench and the edges of the slopes, the minimum technical distances should be observed. If these distances cannot be observed, the trench edges must be fixed. Movement roads must be wide enough for construction machinery and workers without obstacles, if possible, separated and enclosed. Workers must move around a construction object with reflecting vests.

\section{Options for reducing the causes of working at heights and on a rooftop risks}

Working at height on the roof is one of the most dangerous types of work in construction, what is also reflected by statistics on fatal accidents. Similarly to works in trenches, the most significant risk of working on the roof is the absence of collective protective equipment or disassembly. In terms of collective protection means, it is most commonly observed that there is No guarantee of the roof perimeter from falls in case when the worker has not been provided with individual protection means or has committed a mistake through negligence. Collective means of labour protection protect not only workers but also third parties from objects which may fall from the roof.

Before starting construction work on a roof, careful planning and risk assessment would be necessary. The specific nature of the roof works differs, as the height and roofing of houses vary greatly, as well as the changing weather conditions in Latvia have a significant impact. A construction permit should not be received for the replacement of roofing, which means that if the roof structure is not involved in the works, only a proof card is required for replacing the roofing (Building Regulations, 2014).

The most significant risk in the roof works is falling from great height, so collective means of protection should always be provided along the perimeter of the building. The perimeter of the building must be provided with scaffolding in the direction of the slope. It is important to supplement 
the roof scaffolding with a covered sieve which prevents the fall of various objects from the roof in case of strong breeze or a worker's inattentive dropping.

When assembling scaffolding, it is important that:

- the work is carried out by a certified assembler who is familiar with and observes the assembly schemes and solutions of the scaffolding manufacturer. Before the work is carried out, a scaffolding assembly plan is prepared;

- the scaffolding shall be placed on the stable surface so that it does not lose its resilience;

- scaffolding shall be equipped with all necessary safety elements.

In practice, there are cases when scaffolding cannot be placed on the street, in such case one of the solutions for collective protection is to place scaffolding on consoles under the ledge of the building. It is necessary to carry out additional research and resilience to the building's enclosing structure, since the consoles are based on penetrating anchorages in the building's wall structure.

There are situations where it is possible to place the scaffolds only along the part of the building's ledge and the walls of the end are attached to other houses, which makes it impossible to install the scaffolding. In these parts, as well as parts where there is No active operation but movements of workers are possible, it is necessary to install a railing system that is easy to mount and dismantle and also serves as a stable protection. Railings of this type must also be placed around openings in coverings.

In addition to those collective protection means, in order to ensure additional safety, there are anti-fall protective networks which provide additional protection, if one of the above-mentioned means has not worked. Such a solution is not particularly popular in Latvia. Nets may be used under covering openings for different areas where it is possible to fall to a lower level.

A typical risk is the fall of unattached instruments from great height. To reduce this risk, it is recommended not to keep the materials on the roof which can easily change their location, and workers should choose different modern solutions so that the instruments falling out of hand are provided with an anti-falling mechanism.

Working on the roof mostly involves a complicated working area and uncomfortable working poses. To minimize these risks, a variety of mechanisms, such as wooden, aluminium or scaffolding type ladders, can be used that allow to stay in one of the work areas without additional effort. The ladders are usually hooked by the ridge and they can be selected by the required length.

The proposed collective protection solutions contribute significantly to the prevention of fatal accidents, as well as reduce the risks to third parties, while the safety of the workers themselves should certainly provide for personal protective equipment. There are many and different methods of roof coverings, for example, flat roofs are often encased by a method of melting where open fire is used. Metal works use a method of soldering, the surface is purified mechanically or chemically and, respectively, chemical vapours appear, followed by soldering. In order to reduce risks to health and the potential development of an occupational disease, it would be necessary to apply all the necessary personal protective means to the specific nature of the work:

- a chin-strap helmet that ensures that the helmet is not dropped while bending one's head;

- protective footwear S3 with toe protection, the upper part shall ensure that moisture does not penetrate, oil and petrol resistant, anti-static and non-slip soles;

- protective clothing securing against mechanical fittings and appropriate to climate conditions and allowing easy movement;

- protective goggles against mechanical shocks; 
- respirators appropriate for the specific nature of the work;

- hearing aids, easy to use and used, as appropriate, when noise is above $80 \mathrm{~dB}(\mathrm{~A})$;

- gloves against mechanical resistance, tailored to the specific nature of the work and the climate conditions of the moment;

- fall prevention systems (restricting systems, job positioning systems) and fall stop systems.

The reports of the State Labour Inspectorate and practice often show that major infringements relate to disassembly and operation of scaffolding. Before the scaffolding is installed, it is important to prepare the ground, the base where it will be placed. It is important to ensure that the ground is sufficiently stable and does not lead to decay. It is important:

- to test the stability of the ground;

- to seal the bottom or to build a stable base;

- to make sure that works are not carried out in the immediate vicinity, which could create particular risks for the loss of stability of scaffolding;

- to make sure that rain water will not lead to ground erosion;

- use base plates in the case of flat base to prevent slipping;

- scaffolding must not be based on hollow building materials or bending wood parts (Legally NonBinding Guidance..., 2008).

It is mandatory for the assembler to verify their condition before assembling the elements, to replace the damaged parts with the corresponding undamaged ones. For scaffolding in the vicinity of air lines, electrical installations and scaffolding on the roof of high-rises, grounding is recommended. Scaffolding base must be located on a secure base.

Prior to the assembly of scaffolding, the responsible specialist must draw up plans for the assembly, dismantling and use of scaffolding (scaffolding plan), which must include information on the overview and side-view of the structure of the scaffolding, the location of the scaffolding structure at the site (at the building or other site), the dimensions of the scaffolding structure (length, width, height, area placements, diagonal placements, anchorage points and mountings) and restrictions on use. The scaffolding must be assembled, operated, dismantled and maintained in accordance with the requirements of the manufacturer and lessor, the instructions for use, the technical documentation and the scaffolding plan. Scaffolding must be mounted in full assembly (Labour Protection Requirements..., 2014).

\section{Improvements in performing instructions for reducing the causes of risks}

Analysing the causes of accidents in the construction sector, it can be concluded that the causes of accidents involving poor performance or lack of quality of labour protection instructions (lack of compliance with safety regulations or instructions, unsatisfactory instructing and training of workers, use of unacceptable or inappropriate working methods, insufficient attention) are 64,6\%.

In the second half of 2018 the authors had made a survey among employees of more than 10 construction companies in Latvia in the field of labour protection. Survey results showed that $66 \%$ of those surveyed received the full instruction. 11,4 \% are not instructed at all when job duties change. $25,7 \%$ do not receive new instructions, and most mention that the instructions are received in the work area or in the dressing room.

These statistical indicators clearly show that there is need for improvements and arrangements in the conduct of instructions. The success of this process requires a system governing the procedures in which employees should be instructed and their knowledge checked. 
In spite of the implementation of the system, important nuances should be highlighted, which would encourage labour protection instructions to be of better quality and make employees understand them better:

- instructions must be simple and specific without complex words and legislative points;

- instructions must be carried out in rooms intended for them, not at the workplace or in the dressing room;

- the employees must be paid for the time spent on instructions;

- in relation to the fact that a large proportion of employees in Latvia do not understand the Latvian language and are from other countries, it is desirable to perform the instructions in a number of languages, in Latvian and in a language that is understood by the employee;

- the use of easily perceived images, infographic images;

- instructions must be short;

- let the instructed ask questions, if any.

\section{Conclusions, proposals, recommendations}

In carrying out the assessment of the risks of work environment in the field of construction in Latvia, the authors of the work concluded the following.

1) Construction workers are exposed to many and different combinations of risks to the working environment, since very often a number of risks to the working environment are simultaneously exposed and are able to reinforce each other's effects, such as concreting, bricklaying, finishing works etc. The short time limits for carrying out works contribute to this.

2) Accident statistical data indicate that accidents take place in case of a lack of attention of employees and failure to comply with the specified labour protection requirements. These accidents are based on poor instruction and monitoring of the labour protection plan, as well as lack of time and costs that contribute to stress, leading to errors of negligence and forgetfulness. The result is an accident.

3) The most important risk factors for the working environment in construction are: mechanical and traumatism factors, physical factors, chemicals, dust, ergonomic factors, psychosocial factors and biological factors. The main factors leading to accidents include working at a height without collective and personal protective means, falling objects, stumbling (tripping), electrical injuries, collisions with heavy machinery, working with hazardous equipment, working in unforced trenches.

4) Due to resource and time saving, instructions are carried out even in workplaces or dressing rooms, which prevents workers from concentrating and correct perception of instructions. There is No practical demonstration or No verification of the information that has been heard to determine whether the worker has received and understood the information of instruction.

During the project execution stage, monitoring and control of labour protection requirements, including collective and personal protection requirements, should be ensured on the construction site, as well as making sure that all employees in the construction facility are instructed, trained and familiar with the labour protection requirements. It is recommended that the following measures should be taken at the project execution stage.

1) In order to successfully operate a construction company in the field of job protection, the company needs an internal system of labour protection. The system does not need to be international or recognised by any special standards, which requires high costs. 
2) After performing instructions, it is necessary to control the acquired knowledge; the control could be in the form of interactive tests. In order to improve the culture of labour protection on the part of employees, it would be important for the company to create a motivational system for employees. For example, the best employee of the month, who has not violated labour protection requirements or otherwise provided valuable information about problems at the construction site, should be rewarded with paid holidays or sponsored entertainment beyond working hours.

3) To place informative, easily perceivable booklets in the areas of construction sites where active operations are taking place with the most important information regarding the works to be performed. Placed at arm's length, information would serve as an additional means of reducing risks and would not require major investments.

4) To improve the content and presentation of instructions, short briefings should be supplemented with easily perceived practical examples, such as how to properly handle an angle grinder or use a respirator. It is advisable to use images or create instructions in the from of infographics. Instructions should be topical and adapted to the needs of employees. After conducting instructions, it is necessary to check the knowledge of the instructed, for example by means of a test.

\section{Bibliography}

1. Building Regulations (2014). Republic of Latvia Cabinet Regulation No.529, Adopted 2 September 2014.

2. Labour Protection Requirements for Protection of Employees from the Risk Caused by the Noise of the Work Environment (2003). Republic of Latvia Cabinet Regulation No.66. Adopted 4 February 2003.

3. Labour Protection Requirements Working at a Height (2014). Republic of Latvia Cabinet Regulation No.143, Adopted 18 March 2014.

4. Legally Non-Binding Guidance on Best Practices in the Implementation of Directive 2001/45/EK (Working at Height) (2008). Office for Official Publications of the European Communities, Luxembourg. 82 p.

5. Riga Stradins University (2010). Labour Protection Requirements for Road Construction. Riga: Riga Stradins University Institute for Occupational safety and environmental health. $16 \mathrm{p}$.

6. Riga Stradins University (2011). Labour Protection Requirements for Working at Height. Riga: Riga Stradins University Institute for Occupational safety and environmental health. $18 \mathrm{p}$.

7. Riga Stradins University (2016). Work Environment Risks in Construction. Riga: Riga Stradins University Institute for Occupational safety and environmental health. $18 \mathrm{p}$.

8. State Labour Inspectorate (2015). Report to the National Labour Organisation on the Results of the 2014 Performance of the State Labour Inspectorate. Riga, $18 \mathrm{p}$. 